\title{
A Review on Stress Paradigm Use in Physiological Research
}

\begin{tabular}{c} 
Okwute Michael Ochayi ${ }^{* 1}$ and Bond Anyaehie ${ }^{2}$ \\
Received: 11 March, 2021, Accepted: 5 June, 2021, Published: 1 Oct, 2021 \\
\hline 1*Department of Physiology, Faculty of Basic Medical Sciences, Baze University, Abuja, FCT, Nigeria, mykelochayi@yahoo.com \\
2Department of Physiology, Faculty of Basic Medical Sciences, University of Nigeria, Nsukka, Enugu State, Nigeria, bond.anyaehie@unn.edu.ng.
\end{tabular}

\section{Abstract}

Background: stress is an omnipresence phenomenon, and it's set to induce organs damage in most living organisms. The degree of organ damage is difficult to ascertain in humans; this has called for translational studies on animals to deduce the pathways by which stressor induce organ damage.

Aim: To compare the effects poses on the system by the various stress paradigm use in physiological research.

Methods: The literature were sourced from Google Scholar and PubMed database by typing the following keywords; stress, restraint stress, noise stress, heat stress and water immersion; about a 100 paper was read an 45 were careful selected based on relevance and year of publication. $90 \%$ of the papers were within 2015 to 2020 while the remaining $10 \%$ were before 2015.

Results: Literature reviewed shows that restraint and heat stressors have exaggerated widespread effects on most organs ranging from structural alteration of the nervous system, increase coxygenase-2 on the vascular system and alteration of reproductive functions. While water immersion stress is peculiar with gastro intestinal system alteration proven to induce ulceration in experimental rats. Electric foot-shock and noise stress have more profound effects on reproductive organ.

Conclusion: findings of this review showed that during experimental studies, restraint and heat stress have wide range effects on the body systems. While water immersion stress is best use for gastrointestinal studies. Noise and electric foot-shock maybe more relevant for reproductive stress induction.

Keywords: stress, restraint stress, noise stress, water immersion stress, heat stress 


\section{Introduction}

Stress is an inescapable external event that disrupts the biological state of a living organism be it plant, animal, or microorganism (Collier et al., 2017; Calfapietra et al., 2015: Papadimitriou et al., 2015). Since exposure to stress is unavoidable, most living organisms have developed adaptive features that make it possible for them to acclimatize or acclimate to it; some of these adaptive features depend on the type of stress been exposed to, which could be acute or chronic stress (American Psychological Association, 2018). Acute stress is a short-term stress exposure such as traffic jams and arguments among other events we face in our day-to-day activities. Acute stress is driven by homeostatic regulators such as the nervous and endocrine systems respectively. While chronic stress is a longer duration of stress exposure it's driven by homeostatic regulators of the endocrine system. The neuroendocrine system of mammals consists of the brain, the hypothalamus-pituitary-adrenal axis (cortisol, epinephrine, norepinephrine), and the autonomic system (sympathetic nervous system) (Winberg et al., 2016).

However, the mechanism the system employs to coordinate stress can become maladaptive or adaptive due to the effect of certain neurotransmitters released which tend to alter mitochondrial function thereby increasing metabolic rate (Herman, 2020). The increased metabolic rate produces extra free radicals, leading to an imbalance between reactive oxygen species (ROS) generation and anti-oxidant systems. These free radical species result in oxidative damage to cells causing various ill effects on man and animals (Samarghandian et al., 2016).

The ill effect on men and animals is a result of daily exposure to stressors which are; environmental, psychological, and chemical events that lead to a cascade of events that target mitochondrial function. Since 1936 that Hans Seyle came about with a major finding on stress, scientist over the years both in the field of biomedical and psychology research has focused on research aimed at mitigating various harmful events that emanate (resulted) from stress exposure that had led to various organ damage (Zaid et al., 2019; Hartman et al., 2019). 
The need to mitigate this event has birthed the use of various animal models such as rodents for easy evaluation of the damaging effects and therapeutic trials to ameliorate this inescapable event. The use of various animal models in the laboratory has proven to yield results making it possible to target some underpinned damage in a living organism. This review aims to compare the various stress paradigm use in order to induce stress and the effects they poses on the system.

\section{Methods}

This review is developed from scientific articles sourced from Google Scholar and PubMed database by typing the following keywords; stress, restraint stress, noise stress, heat stress and water immersion; 100 papers were read and 45 were selected based on relevance and date of publication. Articles before 2010 were excluded only articles from 2010 to date were used. About $90 \%$ of the articles used were within 2015 to 2021 . While the remaining $10 \%$ were before 2015 .

\section{Results}

\section{Restraint Stress}

Restraint stress is a type of psychological stress model that confined an animal to a fixed place for minutes or hours; it's meant to mimic bedridden patients, prisoners, and desk officer who sit at a place for a long time; In experimental studies, it could be induced by the hind-limb model, wire mesh and Plexiglas (Du et al., 2013; Ochayi et al., 2015). It has gained prominent use in many types of research especially in the developing world with some reporting its deleterious effect on the various systems such as cardiovascular, reproductive, and the nervous system (Hong et al., 2014).

\section{Effect of Restraint Stress on the Cardiovascular System}

Restraint stress induces cardiovascular diseases with its ability to induce endothelial dysfunction as a result of increased vascular contraction via cycloxygenase-2 (COX-2) derived vasoconstrictor prostanoid (Carda et al., 2020). It was also reported to affect the cardiovascular system in the following ways; potentate cardiac and visceral adipose tissue 
inflammation this exacerbates hypertension as well as left ventricular hypertrophy, fibrosis, diastolic dysfunction, and oxidative stress (Matsuura et al., 2015).

\section{Effect of Restraint Stress on the Reproductive System}

The reproductive system which is the organ of procreation and continuity of man and animal as recently attracted a lot of attention and research with regards to stress possibly because of how delicate it's to the existentialism of species. In a study on Gonadotropininhibitory hormone, a hormone that inhibits reproduction; its concentration increases in response to stress (Ernst et al., 2016). However, some of the effects on reproductive organs are sex determinants. In male rats it decreases CYP11AI expression, this decreases testosterone concentration resulting in atrophy of seminiferous tubules and low sperm count (Arun et al., 2016). While in female rats, restraint stress decrease cell counts per blastocyst reduced the number of implantation sites in uteri (Burkuš et al., 2015).

\section{Effect of Restraint Stress on the Nervous System}

The nervous system which is the fastest body control system is not exempted from the deleterious effects observed during restraint induction. Restraint stress alters its structure through increase expression of nitric oxide synthase isoforms observed in multiple brain regions and S-nitrosylation which facilitate neural damage (Foley et al 2019.) It also alters blood-brain barriers (BBB), by modifying the tight junction proteins as well as brain micro vascular endothelial cells( $\mathrm{Xu}$ et al., 2019). Hence, once there is an alteration in brain structure the corresponding effect will be manifested in brain functions. A study conducted by Choubey et al. (2019), has showed that restraint stress (RS) induces anxiety and depressive-like behavior. It is also implicated in the alteration of the learning and memory process; hence, resulting in the cognitive deficit (Ngoupaye et al., 2018). The aforementioned effects of restraint stress on the nervous system could be tired to its ability to induce oxidative damage shown by elevated brain levels of malondialdehyde (MDA), since MDA is an indicator of lipid peroxidation (Salehi et al., 2018). 


\section{Noise Stress}

Noise is described as a vast cacophony of sounds usually above $100 \mathrm{~dB}$, emerging from a work environment, urban traffic, household appliances, and places of worship clubs, and events among others (David et al., 2021). It's unavoidable and has been implicated in an array of disorders such as cognitive impairment, sleep disorders and recently some epidemiological studies have included cardiovascular diseases to some of the effects of noise stress (Munzel et al., 2018). Since noise being an unavoidable environmental stressor there is a need for translational research to be conducted in other to deduce the most vulnerable organs affected by noise stress and possible development and approach to mitigate such effects. In physiological research which has become a hub for preclinical findings, broadband white generators at $100 \mathrm{Db}$ is being used to induce noise stress in the laboratory (Ravidran et al., 2015). This has proven to be highly effective based on the deleterious effect it poses on several systems in the body as follows:

\section{Effect of Noise Stress on the Cardiovascular System}

Since the cardiovascular system is controlled by the autonomic nervous system, one will logically attribute irritating sound called noise to instigate some kind of annoyance that has the tendency to trigger sympathetic response and increases the level of stress hormones which increases heart rate and hence blood pressure (Hahad et al., 2019). However, there is not enough evidence to draw viable proof on how noise alters the cardiovascular system. A study has shown that noise stress decrease diameter of myocardial muscle fibers and thickens the walls of blood via the deposition of collagen fibers (Elgharabawi et al., 2019). Another study also tries to relate diurnal variation and implication of noise stress which they observed that noise stress at night induces vascular damage, uncoupling of endothelial synthase, and infiltration with inflammatory cells (Münzel et al., 2020).

\section{Effect of Noise Stress on the Nervous System}

The nervous system which is the body's first responder to stress plays a crucial role in stress management. However, when it becomes overwhelmed certain disorders set in; a study has shown that $4 \mathrm{~h}$ of noise stress exposure alters 4-HNS neuron expression in the hippocampus (Krishnaeswari et al., 2019). These disorders are linked with the ability of 
noise stress to alter free radicals which differ across several regions of the brain from the cerebral cortex, cerebellum, medulla oblongata, and hypothalamus (Basner et al., 2014). These regions of the brain have the roles they play such as the hippocampus and amygdala nucleus have been linked to control behavior; a study recently shows that exposure to noise stress also triggers anxiety-like behaviors in rats (Ardeshiri-Lordejani et al., 2020).

\section{Effect of Noise Stress on the Reproductive System}

Effect of noise stress on the reproductive organ could be manifested base on some anatomical, physiological or biochemical alteration translated into infertility, mating behavior, ovulation, implantation, fetal growth, and lactation in animals during research. However, exposure of rats to a white noise generator induces a decrease in a hormonal concentration such as FSH and testosterone, and hence resulting in a decreased sperm count, concentration, and motility (Bisong et al., 2018). It also alters the anatomical feature of male reproductive organs such as testicular and epididymis tissues (Bisong et al., 2018). It increases the rate of resorbed embryos, in essence, and induces abortion (Jafari et al., 2017). Exposure to laboratory noise as short as five days has been reported to reduce gonadotropins and sex hormone levels in female mice (Shafiei et al., 2017).

\section{Water Immersion Stress}

Water immersion stress implies means immersing a laboratory animal inside a water top for a minute or hour pending on the type of stress be it acute or chronic stress; this method has been proven experimentally to induce physiological stress (e.g. hunger) and psychological stress (e.g. anger, conditioned fear and anxiety), that can lead to the damage of internal organs shown as follows:

\section{Effect of Water Immersion Stress on the Gastrointestinal System}

The gastrointestinal system tagged as the epicenter for the deleterious effect of water immersion stress on the body. Most research and studies conducted using the laboratory approach of water immersion stress has proven to yield result. A study on microbiota Lachnospiraceae; a causative organism of Crohn's disease, celiac, and the peptic ulcer was found to increase in number when exposed to water immersion stress on mice ( $\mathrm{Li}$ et al., 
2017). While water immersion stress on Wistar albino rats induces a spike in the volume of gastric juice, acid, and decreases $\mathrm{pH}$ of gastric content hence resulting in ulceration (Ahmad et al., 2017). All this mechanism proposed to induce GI ulceration can result from barely $3 \mathrm{~h}$ of water immersion stress under few days in rodents (Sun et al., 2017). The use of the water immersion stress paradigm has contributed immensely to the development of therapeutic targets on the management of ulceration and some other diseases induce; since its impacts cover both the psychological and physiological state of the laboratory animal being used.

\section{Heat Stress}

The thermal neutral zone ranges from $16^{\circ} \mathrm{C}$ to $25^{\circ} \mathrm{C}$ which most living organisms keep up a normal physiological state. However, when the temperature goes above $25^{\circ} \mathrm{C}$ in a tropical climate like India or Congo or goes below $10^{\circ} \mathrm{C}$ in a temperate climate such as Russian/Canada; this high fluctuating threatens the homeostasis state resulting in cold or heat stress (Devargan et al., 2017). It is not uncommon during April to June to have periods of high environmental temperatures often accompanied with high relative humidity in some cities in Nigeria of temperatures above $32^{\circ} \mathrm{C}\left(90^{\circ} \mathrm{F}\right)$, that marks acute heat stress which is associated with the pathology of many diseases (Das et al., 2016). In the laboratories it's induced using a Plexiglas chamber as seen in Plate 4; where a rat is placed inside the chamber with a temperature regulator; which is used to regulate the temperature to induce heat stress based on the desired outcome of research with significant success rate has seen in some of the studies below:

\section{Effect of Heat Stress on the Body System}

Heat stress has been proven to alter not just the physiological state but also biochemical and anatomical structures in the living organism, On the male reproductive system, some studies have shown how it induces testicular damage, loss of germ cell, poor quality of semen production all these are linked with the alteration of antioxidant status posed by the stress (Cao et al., 2015; Hou et al., 2015). The nervous system is not left out on the deleterious effect of heat stress as it was observed to cause degeneration of neuronal and synaptic dendrites of the hippocampus and also decreases neurogenesis; thereby declining 
the rate of cognition (Lee et al., 2015). On the cardiovascular system, it induces apoptosisof the myocardia cells (Chen et al., 2015). The aforementioned studies using heat stress chamber has been proven effective to mimic common heat stress undergo by humans, especially those residing or visiting tropical climate and has led to the development of several therapeutic approaches use to mitigate any possible effect that may result from heat stress.

\section{Electric Foot-Shock Stress}

Electric foot shock stress protocol is a compound stressor with both physical and emotional components. This model includes acute or chronic exposures of shocks on an electrified grid floor in an electric foot shock apparatus. What makes it unique among other laboratory stress induction paradigms is that animals do not habituate to it when compared with other stressors, including noise, heat, restraint, and water immersion. Additionally, it offers an experimental advantage of control over intensity and duration (Bali \&Jaggi, 2015).

\section{Effect of Foot-Shock Stress on Some Systems}

On the nervous system, foot-shock stress induces deleterious effects on the paraventricular nucleus by increasing c-fos cells this promotes the hypothalamic pituitary adrenal(HPA) axis that resuls to adrenal hypertrophy and increase plasma corticosterone, which affects the hippocampus cells and increases its vulnerability to neuropathology (Bonapersona et al., 2021). While on the molecular level it causes changes in glutamatergic receptor subunits, which may suggest early and transient enhancement of AMPA-mediated currents, followed by transient activation of N-methyl-D-aspartat (NMDA) receptors (Bonini et al., 2016). This leads to increase in cytosolic ion resulting to death on neuron

On the cardiovascular system, two-week foot shock exposure significantly increases systolic blood pressure, accompanied by an increase of the plasma concentrations of renin, Ang. II, corticosterone, and thiobarbituric acid reactive substances (TBARS), as well as a decrease in plasma superoxide dismutase (SOD), results to imbalance of oxidants and antioxidants system which may result to oxidative stress and Glutathione Peroxidase 
(GSH-Px) activities decreases the body ability to fight oxidative stress ( (Dong et al., 2015).

On the gastrointestinal tracts (GIT); foot shock stress-induced elevation of endogenous GCs exacerbates $\alpha$-GalCer-initiated hepatic apoptosis through the expansion of liver NKT cells and the up-regulation of hepatocyte Fas antigen (Fan et al., 2021). It also induced hydropic degeneration of hepatocytes, an increase of the nucleus/cytoplasm ratio due to an increase in nuclei and reduction of the cytoplasm area, focal necrosis, and lymph histiocytic infiltration (Fomeneko et al., 2019). Hence, one would have preferable recommend foot-shock stress paradigm to induce stress, but rather unfortunate electricity has become a major limitation to the actualization of such recommendation in our local society here in Nigeria.

\section{Discussion}

Most of the physiological research on stress employed the use of restraint and heat stress across various organ and the effects of both stressors ranges from structural, biochemical and physiological alteration of the various systems (Arun et al 2016; Chen et al., 2015). Most studies on water immersion stress induction were in relation to gastrointestinal tract; this has proven to be effective in the induction of gastric ulcer (Ahmad et al., 2017; Li et al., 2017). On the other hand noise stress and electric foot-shock cannot be specific tied with a particular effect, but according to the literature reviewed, it has more effect on the reproductive systems since they mostly affect both gonadotropin and cytoarchitecture of the gonads in manner not fully proven.

\section{Conclusion}

Throughout this review, several shreds of evidence were provided on how several stress paradigms have proven to be effective in the induction of stress consequence on several organs namely; restraint stress (wire-mesh), water immersion, foot-shock, noise, and heat stress. However, some of these paradigms are peculiar with certain organ damage like water immersion. While others have a widespread effects such as heat and restraint stress and could be use for any stress induction study. 
This review recommends the use of noise, water immersion and electric foot-shock model to evaluate their effects on various systems and also the mechanism by which noise stress alters reproductive organ. 


\section{References}

Ahmad, S. S., Najmi, A. K., Kaundal, M., \&Akhtar, M. (2017). Gastroprotective effect of Thymoquinone on water immersion restraint stress induced ulceration in rats. Drug research, 67(06), 366-372.

Ardeshiri-Lordejani, F., Sharifi, T., Salami, M., Qazanfari, A., \&Soheili, M. (2020). Zinc/Iron oxide nanocomposites: green synthesis, characterization, and evaluation of their effects on anxiety in rats exposed to noise stress. Journal of Nanostructures.

Arun, S., Burawat, J., Sukhorum, W., Sampannang, A., Maneenin, C., \&Iamsaard, S. (2016). Chronic restraint stress induces sperm acrosome reaction and changes in testicular tyrosine-phosphorylated proteins in rats. International Journal of Reproductive BioMedicine, 14(7), 443.

Bali, A., \& Jaggi, A. S. (2015). Electric foot shock stress: a useful tool in neuropsychiatric studies. Reviews in the Neurosciences, 26(6), 655-677.

Basner, M., Babisch, W., Davis, A., Brink, M., Clark, C., Janssen, S., \& Stansfeld, S. (2014). Auditory and non-auditory effects of noise on health. The lancet, 383(9925), 1325-1332.

Bisong, S. A., Ukoh, I. E., Nna, V. U., \&Ebong, P. E. (2018). Vitamin E attenuates nicotine-and noise-induced reproductive impairment in male albino Wistar rats. Andrologia, 50(7), e13050.

Bonapersona, V., Schuler, H., Damsteeg, R. D., Adolfs, Y., Pasterkamp, R. J., van den Heuvel, M. P., ... \& Sarabdjitsingh, R. A. (2021). The mouse brain after foot-shock in 4D: temporal dynamics at a single cell resolution. bioRxiv.

Bonini, D., Mora, C., Tornese, P., Sala, N., Filippini, A., La Via, L., ... \&Gennarelli, M. (2016). Acute footshock stress induces time-dependent modifications of AMPA/NMDA protein expression and AMPAphosphorylation. Neural plasticity, 2016.

Burkuš, J., Kačmarová, M., Kubandova, J., Kokošová, N., Fabianova, K., Fabian, D., ... \& Čikoš, Š. (2015). Stress exposure during the preimplantation period affects blastocyst lineages and offspring development. Journal of Reproduction and Development, 61(4), 325-331.

Calfapietra, C., Peñuelas, J., \& Niinemets, Ü. (2015). Urban plant physiology: adaptationmitigation strategies under permanent stress. Trends in plant science, 20(2), 72-75.

Cao, Y., Li, Y. S., Li, Z. J., Wang, F., \& Li, C. M. (2015). Dietary zinc may attenuate heat-induced testicular oxidative stress in mice via the up-regulation of $\mathrm{Cu}-\mathrm{Zn}$ SOD. Genetics and Molecular Research, 14(4), 16616-16626.

Carda, A. P., Marchi, K. C., Rizzi, E., Mecawi, A. S., Antunes-Rodrigues, J., Padovan, C. M., \&Tirapelli, C. R. (2015). Acute restraint stress induces endothelial dysfunction: the role of vasoconstrictor prostanoids and oxidative stress. Stress, 18(2), 233-243. 
Chen, H. B., Zhang, X. C., Cheng, Y. F., Abdelnasir, A., Tang, S., Kemper, N., \& Bao, E. D. (2015). Association of heat shock protein 70 expressions with rat myocardial cell damage during heat stress in vitro and in vivo. Genet Mol Res, 14(1), 1994-2005.

Choubey, P., Kwatra, M., Pandey, S. N., Kumar, D., Dwivedi, D. K., Rajput, P., ... \&Jangra, A. (2019). Ameliorative effect of fisetin against lipopolysaccharide and restraint stressinduced behavioral deficits via modulation of NF- $\mathrm{BB}$ and IDO1. Psychopharmacology, 236(2), 741-752.

Collier, R. J., Renquist, B. J., \& Xiao, Y. (2017). A 100-Year Review: Stress physiology including heat stress. Journal of dairy science, 100(12), 10367-10380.

Das, R., Sailo, L., Verma, N., Bharti, P., \&Saikia, J. (2016). Impact of heat stress on health and performance of dairy animals: A review. Veterinary World, 9(3), 260.

David, L., Brice, L., Richard, P., Jean Dominique, D., \& Dominique, J. (2021). Seafarers' Occupational Noise Exposure and Cardiovascular Risk. Comments to Bolm-Audorff, U.; et al. Occupational Noise and Hypertension Risk: A Systematic Review and Meta-Analysis. Int. J. Environ. Res. Public Health 2020, 17, 6281. International Journal of Environmental Research and Public Health, 18(3), 1149.

Devarajan, N., Köhler, T., Sivalingam, P., Van Delden, C., Mulaji, C. K., Mpiana, P. T., ... \&Poté, J. (2017). Antibiotic-resistant Pseudomonas spp. in the aquatic environment: A prevalence study under tropical and temperate climate conditions. Water Research, 115, 256-265.

Dong, T., Chen, J. W., Tian, L. L., Wang, L. H., Jiang, R. D., Zhang, Z., ... \& Sun, W. P. (2015). Role of the renin-angiotensin system, renal sympathetic nerve system, and oxidative stress in chronic foot shock-induced hypertension in rats. International journal of biological sciences, 11(6), 652 .

Du, H., Liu, H., \& Xiong, L. (2013). Endogenous auxin and jasmonic acid levels are differentially modulated by abiotic stresses in rice. Frontiers in plant science, 4, 397.

Elgharabawi, G. S., Motawee, M. E., Mourad, S. E., \&Taha, N. M. (2019). Effect of Noise Stress on Lung and Heart of the Adult Albino Rats and the Possible Protective Role of Sulpiride. The Egyptian Journal of Hospital Medicine.

Ernst, D. K., Lynn, S. E., \& Bentley, G. E. (2016). Differential response of GnIH in the brain and gonads following acute stress in a songbird. General and comparative endocrinology, 227, 51-57.

Fan, F., Ai, Y., Sun, T., Li, S., Liu, H., Shi, X., ... \& Cheng, Y. (2021). The role of inflammatory cytokines in anemia and gastrointestinal mucosal injury induced by foot electric stimulation. Scientific Reports, 11(1), 1-9.

Foley, T. D., Koval, K. S., Gallagher, A. G., \& Olsen, S. H. (2019). Potential widespread denitrosylation of brain proteins following prolonged restraint: proposed links between stress and central nervous system disease. Metabolic brain disease, 34(1), 183-189. 
Fomenko, E. V., Bobyntsev, I. I., Ivanov, A. V., Belykh, A. E., Andreeva, L. A., \&Myasoedov, N. F. (2019). Effect of Selank on Morphological Parameters of Rat Liver in Chronic FootShock Stress. Bulletin of experimental biology and medicine, 167(2), 293-296.

Hahad, O., Kröller-Schön, S., Daiber, A., \&Münzel, T. (2019). The cardiovascular effects of noise. DeutschesÄrzteblatt International, 116(14), 245.-

Herman, J. P. (2020). Corticolimbic stress regulatory circuits, hypothalamic-pituitaryadrenocortical adaptation, and resilience. In Stress Resilience (pp. 291-309). Academic Press.

Hou, Y., Wang, X., Lei, Z., Ping, J., Liu, J., Ma, Z., ... \& Li, X. (2015). Heat-stress-induced metabolic changes and altered male reproductive function. Journal of proteome research, 14(3), 1495-1503.

Jafari, Z., Faraji, J., Agha, B. M., Metz, G. A., Kolb, B. E., \&Mohajerani, M. H. (2017). The adverse effects of auditory stress on mouse uterus receptivity and behavior. Scientific reports, 7(1), 1-11.

Krishnaeswari, V., Manikandan, S., \&Vijayakumar, J. (2019). Neuroprotective effect of cranberry extract on chronic noise stress-induced changes in rat hippocampus. Drug Invention Today, 12(8).

Lee, W., Moon, M., Kim, H. G., Lee, T. H., \& Oh, M. S. (2015). Heat stress-induced memory impairment is associated with neuroinflammation in mice. Journal of neuroinflammation, 12(1), 102.

Li, S., Wang, Z., Yang, Y., Yang, S., Yao, C., Liu, K., ... \&Guo, G. (2017). Lachnospiraceae shift in the microbial community of mice faecal sample effects on water immersion restraint stress. AMB Express, 7(1), 82.

Matsuura, N., Nagasawa, K., Minagawa, Y., Ito, S., Sano, Y., Yamada, Y., ... \& Nagata, K. (2015). Restraint stress exacerbates cardiac and adipose tissue pathology via $\beta$-adrenergic signaling in rats with metabolic syndrome. American Journal of Physiology-Heart and Circulatory Physiology, 308(10), H1275-H1286.

Münzel, T., Kroeller-Schön, S., Oelze, M., Gori, T., Schmidt, F. P., Steven, S., ... \&Sørensen, M. (2020). Adverse Cardiovascular Effects of Traffic Noise with a Focus on Nighttime Noise and the New WHO Noise Guidelines. Annual Review of Public Health, 41.

Münzel, T., Schmidt, F. P., Steven, S., Herzog, J., Daiber, A., \&Sørensen, M. (2018). Environmental noise and the cardiovascular system. Journal of the American College of Cardiology, 71(6), 688-697.

Ngoupaye, G. T., Yassi, F. B., Bahane, D. A. N., \& Bum, E. N. (2018). Combined corticosterone treatment and chronic restraint stress lead to depression associated with early cognitive deficits in mice. Metabolic brain disease, 33(2), 421-431. 
Ochayi, M. O., Ayo, J.O., Adelaiye, A. B., Ivang, A \& Manjak, R. Y. (2015). Effects of selenium yeast on anxiety-like behaviours and oxidative stress biomarkers of restraint male Wistar rats. Annals of Medical and Biomedical Science, 2 (1): 28-34

Papadimitriou, K., Alegría, Á., Bron, P. A., De Angelis, M., Gobbetti, M., Kleerebezem, M., ... \&Turroni, F. (2016). Stress physiology of lactic acid bacteria. Microbiol. Mol. Biol. Rev., 80(3), 837-890.

Salehi, A., Rabiei, Z., \&Setorki, M. (2018). Effect of gallic acid on chronic restraint stress-induced anxiety and memory loss in male BALB/c mice. Iranian journal of basic medical sciences, 21(12), 1232.

Samarghandian, S., Azimi-Nezhad, M., Borji, A., \&Farkhondeh, T. (2016). Crocus sativus L.(saffron) extract reduces the extent of oxidative stress and proinflammatory state in aged rat kidney. Prog Nut, 18, 299-310.

Shafiei, A., Ehteram, H., Akbari, H., Kashani, M. M., Beigi, M., Mahabadi, J. A., \&Mazoochi, T. (2017). The effect of chronic noise stress on serum levels of cortisol, gonadotropins, and sexual hormones at the implantation time of mice. Comparative Clinical Pathology, 26(4), 779-784.

Sun, H., Li, R., Xu, S., Liu, Z., \& Ma, X. (2016). Hypothalamic astrocytes respond to gastric mucosal damage induced by restraint water-immersion stress in rat. Frontiers in behavioral neuroscience, 10, 210.

Winberg, S., Höglund, E., \&Øverli, Ø. (2016). Variation in the neuroendocrine stress response. In Fish physiology (Vol. 35, pp. 35-74). Academic Press.

Xu, G. M., Li, Y., Ma, C., Wang, C., Sun, Z., Shen, Y., .. \& Cong, B. (2019). Restraint stressinduced hyperpermeability and damage of the blood-brain barrier in the amygdala of adult rats. Frontiers in molecular neuroscience, 12, 32.

Zhou, Y., Qiu, L., Wang, H., \& Chen, X. (2020). Induction of activity synchronization among primed hippocampal neurons out of random dynamics is key for trace memory formation and retrieval. The FASEB Journal, 34one, 14(8), e0221726. 